\title{
The Biosynthesis of Gangliosides
}

\author{
THE INCORPORATION OF GALACTOSE, $N$-ACETYLGALACTOSAMINE AND \\ $N$-ACETYLNEURAMINIC ACID INTO ENDOGENOUS ACCEPTORS OF SUBCELLULAR \\ PARTICLES FROM RAT BRAIN IN VITRO
}

\author{
By A. ARCE, H. J. MACCIONI AND R. CAPUTTO \\ Departmento de Química Biológica, Instituto de Ciencias Químicas, Ciudad Universitaria, Córdoba, Argentina
}

\author{
(Received 20 August 1970)
}

\begin{abstract}
Gangliosides bound to subcellular particles from rat brain were labelled by incubation of the particles (i) with CMP $-N\left[{ }^{3} \mathrm{H}\right]$-acetylneuraminic acid and (ii) simultaneously, with CMP- $\left[{ }^{3} \mathrm{H}\right]$-acetylneuraminic acid and UDP- $N$-acetyl$\left[{ }^{14} \mathrm{C}_{1}\right]$ galactosamine or with CMP- $N\left[{ }^{3} \mathrm{H}\right]$-acetylneuraminic acid and UDP-[U-14 $\left.\mathrm{C}\right]-$ galactose. Analysis of the labelled gangliosides showed that in (i), (a) the labelling was mostly in the neuraminidase-labile sialyl groups, (b) rigid relationships exist between the enzymes and the sialyl acceptors; the enzymes are not free to interact with all the specific substrates present in the preparation and $(c)$ the precursor of the trisialoganglioside was the major disialoganglioside with a sialyl $2 \rightarrow 8$ sialyl group. In (ii), (a) precursor-product relationships between the main pools of each ganglioside apparently do not exist, (b) for the labelling of Tay-Sachs ganglioside the amount formed from hematoside was at least 2.5 times that from aminoglycolipid and $(c)$ the major monosialoganglioside was the precursor for the major disialoganglioside with a sialyl $2 \rightarrow 8$ sialyl group.
\end{abstract}

The gangliosides are membrane constituents; however, very few membrane models have been proposed in which these compounds are considered (Lehninger, 1968) and we know of no report in which their synthesis is studied as part of a growing or turning-over membrane. A pathway for the biosynthesis of the carbohydrate chain of the gangliosides was proposed by Kaufman, Basu \& Roseman $(1966,1968)$ and a different one by Kanfer, Blacklow, Warren \& Brady (1964), Yip \& Dain (1969) and Handa \& Burton (1969). These pathways have been worked out from reactions occurring between water-soluble donors of glycosyl groups and lipid-soluble acceptors, catalysed by particulate preparations in a medium containing detergents which presumably altered the structures of the membranes. By using this method, possible steps for the synthesis are shown, but the natural relationships of the enzymes with their substrates are disregarded. The medium surrounding the membranes in vivo may convey the different substrates into contact with the enzymes as in the experiments with solubilized acceptors, but these also may be built attached to the membranes so that there are no interchanges with the pools of free intermediates. These different situations are important in determining the ratio of labelling of pools of metabolites related as precursor and product. If the precursor was obtained from a free pool, typical precursor-product relationship should be demonstrated; if the precursor was built and remained bound to the same particle that builds the product, non-typical relationship may be obtained. In the biosynthesis of neuraminyl-lactose, discrepancies between results of experiments in vitro and in vivo were explained because the synthesis obtained with free lactose, as carried out in vitro, is very small compared with the synthesis occurring when the synthesis of lactose and the binding of the sialyl group is carried out by the same enzyme complex (Barra, Cumar \& Caputto, 1969).

The present paper describes kinetic studies on the relationships between the enzymes and their endogenous substrates. It also deals with the incorporation of sialyl, galactosaminyl and galactosyl groups into endogenous acceptors of intact brain particles, to complete most of their different types of gangliosides. Distribution of labelling in endogenous Tay-Sachs ganglioside and multisialoganglioside in particles exposed to labelled donors in the supernatant are given. An important feature of the system used is that, similar to what occurs in vivo (Suzuki \& Korey, 1964), the pools of different gangliosides are built largely independently of each other; this probably reflects the similarity of conditions in which the acceptors are in vivo and in 
the particles. Another important observation in vivo, namely that in rats that had been given $\left[{ }^{14} \mathrm{C}\right]$ glucose the neuraminidase-resistant sialyl group is more labelled than the neuraminidaselabile sialyl group (Suzuki \& Korey, 1964; A. Arce, H. J. Maccioni \& R. Caputto, unpublished work), has not been reproduced. No explanation can be offered at this moment for this discrepancy between labelling in vivo and all the pathways worked out from experiments in vitro. In any case, the relative labelling of the different endogenous ganglio sides, and their components, are bound to be important in determining the pathway of synthesis of these compounds.

\section{EXPERIMENTAL}

Preparation of particles. Brains from 15-day-old rats killed by decapitation were washed twice with several volumes of $50 \mathrm{~mm}$-tris-HCl buffer (pH 7.4)-0.1 $\mathrm{M}-\mathrm{KCl}$ at $4^{\circ} \mathrm{C}$ and homogenized in $10 \mathrm{vol}$. of the same buffer. The homogenate was centrifuged at $800 \mathrm{~g}$ for $10 \mathrm{~min}$; the pellet was discarded and the supernatant was centrifuged at $100000 \mathrm{~g}$ for $30 \mathrm{~min}$. The sediment from this last centrifugation was homogenized with $10 \mathrm{vol}$. of the same buffer as above and recentrifuged; the pellet was finally suspended in $0.1 \mathrm{M}$-potassium phosphate buffer, $\mathrm{pH} 6.8$, to a protein concentration of $2.5 \mathrm{mg} / \mathrm{ml}$.

In cases where the distribution of radioactivity in different gangliosides was studied, larger amounts of particles were needed; better yield of particles was obtained when the brains were homogenized in $0.32 \mathrm{M}$-sucrose and centrifuged at $1000 \mathrm{~g}$ for $10 \mathrm{~min}$, followed by the procedure described above but with $0.32 \mathrm{M}$-sucrose in place of the tris-HCl-KCl solution. The particles were suspended in $0.32 \mathrm{~m}$-sucrose-20 m M-potassium phosphate buffer, $\mathrm{pH} 6.8$; the total volume was $1 \mathrm{ml} / \mathrm{g}$ of brain used as starting material.

The method of Eichberg, Whittaker \& Dawson (1964) was followed for the preparation of subcellular organelles used to study the distribution of sialyltransferase.

Determination of sialyltransferase activity. The incubation system contained, in a total volume of $0.5 \mathrm{ml}, 40 \mu \mathrm{mol}$ of potassium phosphate buffer, $\mathrm{pH} 6.8 ; 5 \mu \mathrm{mol}$ of $\mathrm{MgCl}_{2}$; $10 \mathrm{nmol}$ of CMP-N $\left[{ }^{14} \mathrm{C}\right]$-acetylneuraminic acid (sp. radioactivity, $9 \times 10^{6} \mathrm{c} . \mathrm{p} . \mathrm{m} . / \mu \mathrm{mol}$ ) and enzyme preparation equivalent to $1 \mathrm{mg}$ of protein. The incubation was carried out at $37^{\circ} \mathrm{C}$ in test-tubes covered with waxed paper. To stop the reaction, $20 \mathrm{vol}$. of chloroformmethanol $(2: 1, v / v)$ was added and the mixture vigorously shaken; the mixture was filtered through paper and the filtrate was passed through a column containing $2 \mathrm{~g}$ of Sephadex G-25 equilibrated with chloroform-methanolwater (12:6:0.9, by vol.) by the method of Wells \& Dittmer (1963). The column was washed with $2 \mathrm{ml}$ of the same solvent mixture, the eluates and the washing were dried into vials and the radioactivity was measured.

Isolation and characterization of labelled products. For the study of the distribution of radioactivity into each ganglioside, the particles prepared in sucrose (see above) were incubated with $\mathrm{CMP}-N\left[{ }^{3} \mathrm{H}\right]$-acetylneuraminic acid or with CMP- $N\left[{ }^{3} \mathrm{H}\right]$-acetylneuraminic acid and UDP- $N$ - acetyl $\left[{ }^{14} \mathrm{C}_{1}\right]$-galactosamine or with CMP-N $\left[{ }^{3} \mathrm{H}\right]$-acetyl neuraminic acid and UDP- $\left[\right.$ U- $\left.{ }^{14} \mathrm{C}\right]$ galactose under conditions that will be stated for each case. After inactivation of the incubation system by addition of $20 \mathrm{vol}$. of chloroform-methanol $(2: 1, v / v)$ the suspension was filtered and the filtrate was mixed with 0.2 vol. of water by the method of Folch, Lees \& Sloane-Stanley (1957). The upper phase was concentrated in a rotary evaporator at room temperature and dialysed for $96 \mathrm{~h}$ against tap water and then for $24 \mathrm{~h}$ against distilled water.

The dialysed upper phase was freeze-dried and the residue dissolved in approx. $10 \mathrm{ml}$ of chloroformmethanol-water (12:6:0.9, by vol.); any insoluble material was washed twice with the same solvent mixture and then eliminated by centrifugation. The soluble fractions were pooled and the freeze-drying and dissolving procedures repeated twice. The solution of the crude ganglioside mixture was passed through a Sephadex G-25 column (Wells \& Dittmer, 1963) to eliminate any remaining non-lipid contaminants. The ganglioside mixture was subjected to t.l.c. on silica gel $\mathrm{G}$ (Merck) with chloroformmethanol-20\% $\mathrm{NH}_{3}(60: 35: 8$, by vol.) as solvent. To locate the various gangliosides a strip of about $2 \mathrm{~cm}$ was cut at the border of the plate and stained with the resorcinol reagent (Svennerholm, 1957); the rest of the plate was exposed to iodine vapour and the zones positive to both the resorcinol and iodine reagents were scrapped; six zones were separated each of which migrated to the same position as standard samples of respectively G Lac $1\left(G_{M 3}\right)$,* G GNTr $1\left(G_{M 2}\right), \quad$ G GNT $1\left(G_{M 1}\right)$, G GNT $2 a\left(G_{D 1 a}\right)$, G GNT $2 b\left(G_{D 1 b}\right)$ and G GNT $3\left(G_{T 1}\right)$. Penick, Meisler \& McCluer (1966) found, with the solvent used, that $G$ Lac 2 runs slightly below G GNT $1\left(G_{M_{1}}\right)$, and G GNTr 2 between G GNT $2 b\left(G_{D 1 b}\right)$ and G GNT2a

* Abbreviations: NANAc, $N$-acetylneuraminic acid. For gangliosides, the abbreviation system based on structural considerations (Wiegandt, 1968) has been used. The more commonly used nomenclature suggested by Svennerholm (1964) based on chromatographic mobility has been added in parentheses: hematoside $G$ Lac $1\left(G_{M 3}\right)$, $N$ - acetylneuraminyl - $(2 \rightarrow 3)$ - galactosyl - $(1 \rightarrow 4)$ - glucosylceramide; G Lac $2, N$-acetylneuraminyl-( $2 \rightarrow 8)$ - $N$-acetylneuraminyl - $(2 \rightarrow 3)$ - galactosyl - $(1 \rightarrow 4)$ - glucosylceramide ; Tay-Sachs ganglioside G GNTr $1\left(\mathrm{G}_{\mathrm{M} 2}\right), N$-acetylgalactosaminyl - $(1 \rightarrow 4)$ - $[N$ - acetylneuraminyl - $(2 \rightarrow 3)]$-galactosyl$(1 \rightarrow 4)$-glucosylceramide; G GNTr 2, $N$-acetylgalactosaminyl-(1 $\rightarrow 4)$ - $[N$-acetylneuraminyl- $(2 \rightarrow 8)$ - $N$-acetylneuraminyl - $(2 \rightarrow 3)$ ] - galactosyl - $(1 \rightarrow 4)$ - glucosylceramide ; monosialoganglioside G GNT $1\left(G_{M 1}\right)$, galactosyl-( $\left.1 \rightarrow 3\right)$ $N$-acetylgalactosaminyl - $(1 \rightarrow 4)$ - [ $N$ - acetylneuraminyl $(2 \rightarrow 3)]$-galactosyl-(1 $\rightarrow 4)$-glucosylceramide; disialoganglioside G GNT 2a $\left(\mathrm{G}_{\mathrm{D}_{1 \mathrm{a}}}\right), \quad N$-acetylneuraminyl-(2 $\left.\rightarrow 3\right)$ galactosyl - ( $1 \rightarrow 3$ ) - $N$-ace tylgalac tosaminyl - $(1 \rightarrow 4)$ - [ $N$ acetylneuraminyl - $(2 \rightarrow 3)]$-galactosyl - $(1 \rightarrow 4)$-glucosylceramide; disialoganglioside G GNT $2 \mathrm{~b}\left(\mathrm{G}_{\mathrm{D}_{1 \mathrm{~b}}}\right)$, galactosyl( $1 \rightarrow 3$ ) - $N$-acetylgalactosaminyl-( $1 \rightarrow 4)$ - $[N$-acetylneuraminyl - $(2 \rightarrow 8)-N$ - acetylneuraminyl - $(2 \rightarrow 3)]$ - galactosyl $(1 \rightarrow 4)$-glucosylceramide; trisialoganglioside G GNT 3 $\left(\mathrm{G}_{\mathrm{T} 1}\right), \quad N$-acetylneuraminyl- $(2 \rightarrow 3)$-galactosyl-( $\left.1 \rightarrow 3\right)-N$. acetylgalactosaminyl-(1 $\rightarrow 4)$-[ $N$-acetylneuraminyl-(2 $\rightarrow 8)$ $N$ - acetylneuraminyl - $(2 \rightarrow 3)]$ - galactosyl - $(1 \rightarrow 4)$-glucosylceramide. Aminoglycolipid, G GNTr, $N$-acetylgalactosaminyl-(1 $\rightarrow 4)$-galactosyl-( $1 \rightarrow 4)$-glucosylceramide. 
$\left(G_{D 1 a}\right)$. The silica from the zones where $G$ Lac 2 and G GNTr 2 were expected was not taken. The silica from each of the other zones was suspended in chloroformmethanol-water (10:10:3, by vol.) (Ledeen, Salsman \& Cabrera, 1968), placed in a column and washed with about $20 \mathrm{vol}$. of the same solvent mixture. Each eluate was evaporated to dryness in a rotary evaporator at $35^{\circ} \mathrm{C}$; the residuewas again subjected to t.l.c., $3 \mu \mathrm{mol}$ or less of ganglioside NANAc being placed on a plate $(20 \mathrm{~cm} \times 20 \mathrm{~cm}$; $0.27 \mathrm{~mm}$ thick). In some cases some gangliosides were chromatographed three or four times before they appeared satisfactorily homogenous when sprayed with the resorcinol reagent. Authentic G GNTr $1\left(G_{M 2}\right)$ was isolated from the brain of a patient with Tay-Sachs disease as follows. Total gangliosides were obtained as described above; the upper phase was made $0.15 \mathrm{M}$ with respect to $\mathrm{KCl}$ and partitioned twice with theoretical lower phase (Gatt, 1965); from the pooled lower phases G GNTr $1\left(G_{M 2}\right)$ was purified by t.l.c.

Determination of the specific radioactivities of the neuraminidase-labile and resistant $\mathrm{N}\left[{ }^{3} \mathrm{H}\right]$-acetylneuraminic acid. Each of the fractions isolated as described above, corresponding to $G \operatorname{Lac} 1\left(G_{M 3}\right)$, G GNTr $1\left(G_{M 2}\right)$, G GNT 1 $\left(G_{M 1}\right)$, G GNT 2a $\left(G_{D 1 a}\right)$, G GNT $2 b\left(G_{D 1 b}\right)$ and G GNT 3 $\left(G_{T 1}\right)$, was treated as follows: the total of $G$ Lac $1\left(G_{M 3}\right)$ and $G$ GNTr $1\left(G_{M_{2}}\right)$ obtained (about 0.1 and $0.05 \mu \mathrm{mol}$ respectively) and $0.3-1 \mu \mathrm{mol}$ of the major gangliosides were dried in test tubes; to each tube $66 \mu \mathrm{mol}$ of sodium acetate-acetic acid buffer, $\mathrm{pH} 5.2$, and $40 \mu \mathrm{g}$ of Clostridium perfringens neuraminidase (Sigma, type VI) were added (Burton, 1963). The total volume was $0.25 \mathrm{ml}$. The mixtures were incubated for $3 \mathrm{~h}$ at $37^{\circ} \mathrm{C}$. After incubation the mixtures were transferred to cellophan tubes and dialysed for a total of $12 \mathrm{~h}$ against three successive portions of $4 \mathrm{ml}$ of water. The diffusates containing the neuraminidase-labile $N$-acetylneuraminic acid were stored. To isolate the monosialogangliosides formed during the incubation with neuraminidase, the dialysis residues were run on t.l.c. under the same conditions as before. The amounts isolated showed that at least $90 \%$ of multisialogangliosides were converted into $G$ GNT $1\left(G_{M 1}\right)$ whereas the original G GNT $1\left(G_{M 1}\right)$ was recovered unchanged; G GNTr 1 $\left(G_{M 2}\right)$ was not run on t.l.c. but passed through a Sephadex G-25 column (Wells \& Dittmer, 1963).

Each purified monosialoganglioside was hydrolysed for $2.5 \mathrm{~h}$ at $80^{\circ} \mathrm{C}$ in $0.25 \mathrm{ml}$ of $0.05 \mathrm{M}-\mathrm{H}_{2} \mathrm{SO}_{4}$. After this treament the neuraminidase-resistant NANAc was separated by dialysis. The fractions containing free NANAc were passed through columns $(0.5 \mathrm{~cm} \times 5 \mathrm{~cm})$ of, successively, Dowex $50\left(\mathrm{H}^{+}\right.$form) and Dowex 1 (formate form). After washing the columns with $30 \mathrm{ml}$ of water, NANAc was eluted from the Dowex-l columns with M-formic acid; the formic acid was removed by freeze-drying and the residue was dissolved in water for NANAc determinations and radioactivity counting. All the radioactivity recovered from the columns migrated together with authentic NANAc in co-chromatography experiments. To determine the specific radioactivities of the different labile NANAc moieties of G GNT $3\left(G_{T 1}\right)$, the observation of Svennerholm (1963) on their different susceptibility to neuraminidase was applied; G GNT $3\left(G_{T 1}\right)$ was incubated with neuraminidase in the same conditions described above, but with a tenfold diluted enzyme preparation and for $15 \mathrm{~min}$ only. The reaction was stopped by adding $4 \mathrm{ml}$ of chloroform-methanol $(2: 1, \mathrm{v} / \mathrm{v})$; the solvent was evaporated and the residue was subjected to t.l.c.; the G GNT $2 b\left(G_{D 1 b}\right)$ obtained from G GNT $3\left(G_{T 1}\right)$ was isolated from the plate and treated again with neuraminidase, by using the standard incubation system. The specific radioactivity of the NANAc bound to the terminal galactose was determined by the difference of specific radioactivities between total labile NANAc from G GNT $3\left(\mathrm{G}_{\mathrm{T} 1}\right)$ and labile NANAc from their corresponding G GNT $2 b\left(G_{D 1 b}\right)$.

Determinations of specific radioactivities of doublelabelled compounds. When a ganglioside was doubly labelled the specific radioactivities were determined directly on the intact compound isolated as described above.

Preparation and purification of labelled CMP-Nacetylneuraminic acid and lactosylceramide. CMP-N. acetylneuraminic acid was prepared by the method of Roseman (1962) with the modification of Arce, Maccioni \& Caputto (1966); CMP-N-acetylneuraminic acid was isolated free from NANAc, proteins and CTP by passing the preparation through a DEAE-cellulose column and eluting the CMP- $N$-acetylneuraminic acid with an increasing concentration of $\mathrm{LiCl}$ (Warren \& Blacklow, 1962). To eliminate $\mathrm{LiCl}$, the dried eluate, containing approx. $3.5 \mu \mathrm{mol}$ of CMP- $N$-acetylneuraminic acid, was taken up in the minimal amount of ethanol $(15 \mathrm{ml})$ and the salt suspension deposited on the top of a column $(2.5 \mathrm{~cm} \times 46 \mathrm{~cm})$ of Whatman cellulose powder that had been washed with $0.1 \mathrm{M}$-tris-acetate buffer, $\mathrm{pH} 7.6$, and then equilibrated with ethanol. The column was washed with ethanol until no more $\mathrm{Cl}^{-}$could be detected in the washing when it was tested with $\mathrm{AgNO}_{3}$ (approx. $600 \mathrm{ml}$ of ethanol was needed); after this, CMP- $N$-acetylneuraminic acid was eluted from the column with $0.2 \mathrm{~mm}$-trisacetate buffer, pH 7.6; fractions $(20 \mathrm{ml})$ were collected and checked for radioactivity and extinction at $270 \mathrm{~nm}$. The fractions containing radioactivity and absorbing at $270 \mathrm{~nm}$ were pooled and freeze-dried. Determination of free NANAc in the pool of nucleotide indicated that no more than $8-10 \%$ of the nucleotide was hydrolysed. The absorption spectrum was typical for cytidine and the cytidine/NANAc molar ratio was 1.23.

Lactosylceramide was prepared as described by Cumar, Barra, Maccioni \& Caputto (1968).

Chemical determinations. Free sialic acid was determined by the method of Warren (1959). In some cases the resorcinol reaction was used to determine bound NANAc; it was carried out by the method of Svennerholm as modified by Miettinen \& Takki-Luukkainen (1959). Protein was determined by the method of Lowry, Rosebrough, Farr \& Randall (1951); bovine serum albumin was used as standard, unless indicated.

Measurement of radioactivity. Determinations of radioactivity were carried out in a Beckman model L-S $200 \mathrm{~B}$ liquid-scintillation spectrometer equipped with external standard. Determinations of radioactivity of double-labelled compounds were carried out by using the channel windows for counting ${ }^{3} \mathrm{H}$ and ${ }^{14} \mathrm{C}$ radioactivities separately. The samples were evaporated in vials, the residues dissolved in $0.1 \mathrm{ml}$ of water and $5 \mathrm{ml}$ of dioxan containing $10 \%$ of naphthalene and $0.5 \%$ of 2,5 -diphenyloxazole was added. The error in the radioactivity counting was less than $5 \%$; the efficiency was, for ${ }^{3} \mathrm{H}, 30-35 \%$, for 
${ }^{14} \mathrm{C}, 92 \%$ as determined by external standardization, and for ${ }^{14} \mathrm{C}$ above ${ }^{3} \mathrm{H}, 58-62 \%$.

\section{RESULTS}

Sialyltransferase activity of different subcellular organelles. In a previous report of the distribution of sialyltransferase activity in different subcellular organelles, the crude mitochondrial fraction was used (Arce et al. 1966). Since the difference in the transferase activity between mitochondria and synaptosomes can be meaningful from the physiological point of view, an experiment was run to measure the activity in both fractions. The results showed (Table 1) that the specific activity toward endogenous acceptors was about two- to three-fold higher in the mitochondria than in the other fractions whereas the specific activity with exogenous lactosylceramide as acceptor was somewhat higher in myelin than in the other fractions. In any case, the differences were small enough to justify the conclusion that the sialyltransferase activity is rather evenly distributed in all the subcellular particles.

Kinetic studies with endogenous acceptors. (a) Time curve of $N\left[{ }^{14} \mathrm{C}\right]$-acetylneuraminic acid incorporation. Fig. 1 shows that the transference of NANAc from CMP- $N$-acetylneuraminic acid to acceptors attached to brain subcellular particles occurred at two distinct rates. During the initial period the velocity was relatively high, but at 8$10 \mathrm{~min}$ an apparent inactivation occurred and the reaction proceeded, until the experiment was terminated, at a rate 5 times lower than in the initial period. Three causes may have possibly been responsible for this apparent inactivation, namely enzyme inactivation, destruction of CMP- $N\left[{ }^{14} \mathrm{C}\right]$ acetylneuraminic acid or depletion of acceptors. Enzyme inactivation was discounted since the enzymic activity of particles preincubated for
$15 \mathrm{~min}$ at $37^{\circ} \mathrm{C}$ in the absence of CMP $-N\left[{ }^{14} \mathrm{C}\right]-$ acetylneuraminic acid (but in otherwise identical conditions as in the incubation system) did not show any significant difference of activity with particles of the same batch maintained at $0-4^{\circ} \mathrm{C}$. Destruction of CMP- $N\left[{ }^{14} \mathrm{C}\right]$-acetylneuraminic acid was discounted because determination of NANAc by the method of Warren \& Blacklow (1962) showed that after $15 \mathrm{~min}$ of incubation approx. $96 \%$ of $N\left[{ }^{14} \mathrm{C}\right]$ acetylneuraminic acid was still bound in a linkage

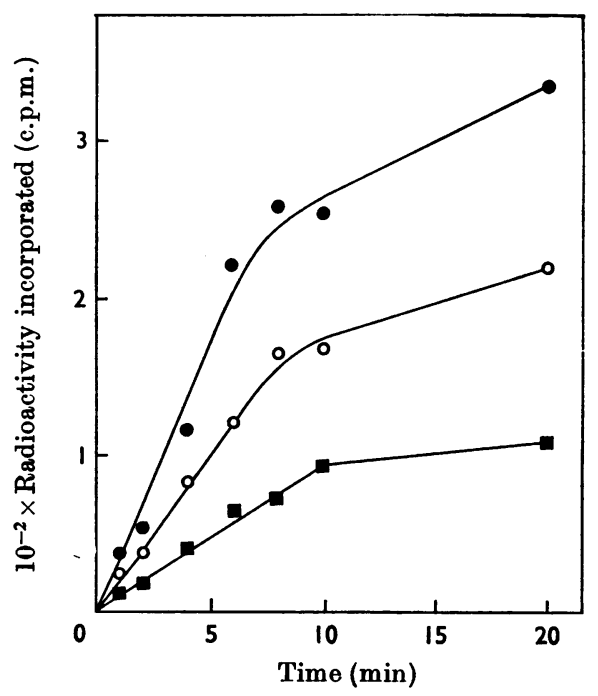

Fig. 1. Incorporation of $N\left[{ }^{14} \mathrm{C}\right]$-acetylneuraminic acid into endogenous acceptors from particulate enzyme preparations as a function of time. The assay mixtures contained: E, $0.2 \mathrm{mg}$ of protein; $0,0.4 \mathrm{mg}$ of protein; $\bullet, 0.6 \mathrm{mg}$ of protein. Other assay conditions were as described in the Experimental section.

\section{Table 1. Sialyltransferase activity in various subcellular particles of rat brain}

The incubation system contained, in a total volume of $0.5 \mathrm{ml}, 40 \mu \mathrm{mol}$ of potassium phosphate buffer, pH6.8, $50 \mathrm{nmol}$ of CMP. $N\left[{ }^{14} \mathrm{C}\right]$-acetylneuraminic acid (specific radioactivity $1 \times 10^{6} \mathrm{c} . \mathrm{p} . \mathrm{m} . / \mu \mathrm{mol}$ ) and particulate enzyme preparation equivalent to $0.5 \mathrm{mg}$ of tyrosine. The incubation was carried out at $37^{\circ} \mathrm{C}$ for $1 \mathrm{~h}$. For this experiment radioactivity was measured in a gas-flow counter. Particles were prepared by the method of Eichberg et al. (1964). The values in the presence of added lactosylceramide $(0.1 \mu \mathrm{mol})$ are corrected for the endogenous values.

\section{Particles \\ Light myelin \\ Synaptosomes \\ Mitochondria}

Microsomes

\section{Addition}

None

Lactosylceramide

None

Lactosylceramide

None

Lactosylceramide

None

Lactosylceramide
Incorporation

(c.p.m./mg of tyrosine)

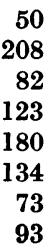


whose stability was identical with that of CMP- $N$ acetylneuraminic acid. After incubation of CMP$N\left[{ }^{14} \mathrm{C}\right]$-acetylneuraminic acid with brain particles for $15 \mathrm{~min}$ approx. $2 \%$ of this compound was converted into $N$-acetylmannosamine; this was identified by paper chromatography with two different solvents and it was evaluated by radioactivity counting.

Since enzyme inactivation and CMP- $N$-acetylneuraminic acid destruction could be discounted as the causes of inactivation of the system, depletion of these acceptors or any other mechanism by which they become unaccessible remained as the most probable cause. Provided that this is correct, it was notable that the reaction followed a linear curve up to the breaking point (zero-order reaction) indicating that the enzyme was saturated with the endogenous acceptor at any concentration available. The nature of the substrate for the slow reaction of the final period has not been determined; this reaction probably was due to renewal of NANAc on the same gangliosides completed in the first period but it has not been excluded that it measured the transference of NANAc to a slow-reacting acceptor.

(b) Enzyme-concentration curve. In the transference of sialyl groups to endogenous acceptors of brain particles (Fig. 2) the plot of initial velocity versus enzyme concentration was linear; this showed that in our particulate system each particle was a

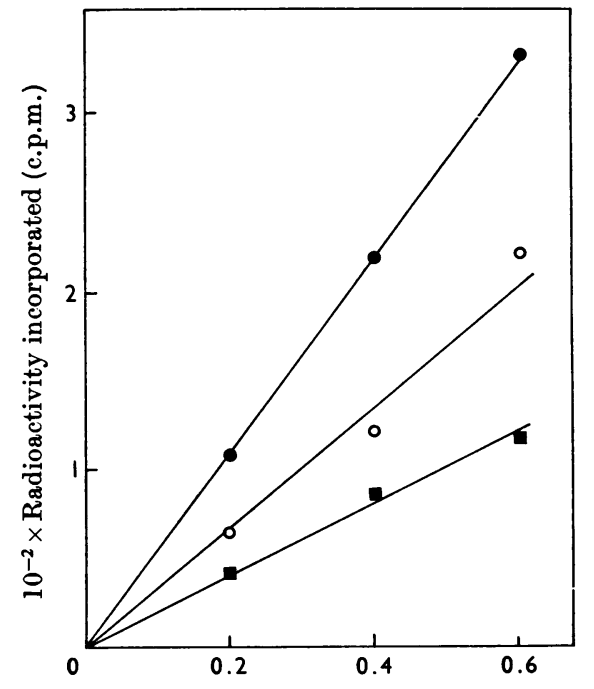

Conen. of enzyme preparation (mg of protein)

Fig. 2. Incorporation of $N\left[{ }^{14} \mathrm{C}\right]$-acetylneuraminic acid into endogenous acceptors as a function of concentration of the particulate enzyme preparation. Incubation times were: $\square, 4 \mathrm{~min}$; $\bigcirc, 6 \mathrm{~min}$;, $20 \mathrm{~min}$. Other assay conditions were as described in the Experimental section. compartment in the sense that the enzymes from one particle did not interact with the substrates of others. If this were not so the compound effect of a free enzyme and substrate system (Reiner, 1959) should have been observed.

(c) Heat-inactivation. Test tubes $(0.5 \mathrm{~cm}$ diam.) containing particles obtained as stated in the Experimental section were immersed in a $52^{\circ} \mathrm{C}$ bath for periods of from 15 to $70 \mathrm{~s}$; after these periods the tubes were immersed immediately in an ice-water bath where they were kept until used. The resulting preparations were tested by incubating for $6 \mathrm{~min}$ in the presence of CMP $-N\left[{ }^{14} \mathrm{C}\right]$-acetylneuraminic acid; results showed that the inactivation amounted to 13,42 and $57 \%$ after 15,45 and $70 \mathrm{~s}$ in the $52^{\circ} \mathrm{C}$ water bath, respectively. A preparation inactivated for $60 \mathrm{~s}$ at $52^{\circ} \mathrm{C}$ was compared with the original unheated preparation; it was found that the percentage of activity measured in the partially inactivated preparation relative to the original preparation was the same at 10, 20 and $60 \mathrm{~min}$ of incubation with CMP- $N$-acetylneuraminic acid as donor and that the period at which the breaking point of the incorporation was reached was the same for the heated and the original preparations (Fig. 3). Further, provided that the incorporation at $10 \mathrm{~min}$ measured the velocity of reaction whereas the incorporation at $60 \mathrm{~min}$ measured the total acceptor capacity of the preparation, it appeared that the decrease in the total amount of NANAc incorporated

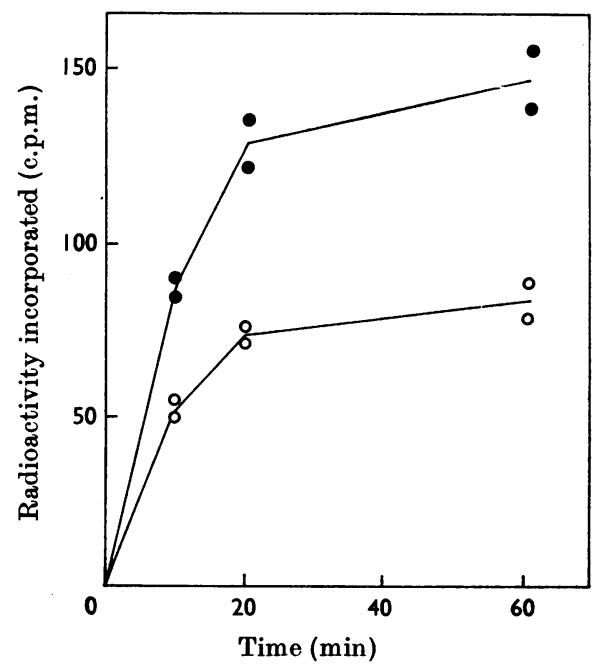

Fig. 3. Incorporation of $N\left[{ }^{14} \mathrm{C}\right]$-acetylneuraminic acid into endogenous acceptors from heat-inactivated particulate enzyme preparation. $\bullet$, Unheated control; $O$, heated at $52^{\circ} \mathrm{C}$ for $60 \mathrm{~s}$. Particulate preparation contained $0.5 \mathrm{mg}$ of protein $/ \mathrm{ml}$. Other assay conditions were as described in the Experimental section. 
into the heated preparation was proportional to the decrease in the enzyme activity. This was noteworthy because it showed that the heat inactivation of the enzyme produced a proportional elimination of acceptor molecules even if these are not heatlabile substances.

(d) Effect of exogenous acceptors on the incorporation of $N$-acetylneuraminic acid into endogenous acceptors. It is known that rat brain (Arce et al. 1966) and embryonic chicken brain (Kaufman et al. 1966) preparations catalyse the transference of NANAc from CMP- $N$-acetylneuraminic acid to lactosylceramide or lactose to form, respectively, hematoside or neuraminyl-lactose. In the present work it was investigated if in the presence of exogenous acceptors the incorporation of NANAc by the endogenous acceptors was inhibited. The specific radioactivity of each ganglioside after 5 and $15 \mathrm{~min}$ incubation was determined by the method of Suzuki \& Chen (1967). Addition of lactosylceramide $(0.4 \mathrm{~mm})$ or lactose $(16 \mathrm{~mm})$ had no effect on the rate of incorporation of NANAc to form the major mono-, di, or tri-sialogangliosides from endogenous acceptors. Conversely, attempts were made to elucidate whether the activity of the enzyme towards endogenous acceptors interfered with its activity towards exogenous lactosylceramide. The acceptor capacity of a sample of particles was exhausted by incubation for $10 \mathrm{~min}$ with CMP- $N\left[{ }^{14} \mathrm{C}\right]$-acetylneuraminic acid and the activity of these particles was compared with the activity of another sample preincubated in the absence of CMP- $N\left[{ }^{14} \mathrm{C}\right]$-acetylneuraminic acid. The incorporation of $N\left[{ }^{14} \mathrm{C}\right]$-acetylneuraminic acid into exogenous lactosylceramide $(0.2 \mu \mathrm{mol}$ dissolved in $0.5 \mathrm{mg}$ of Tween 20) was measured at different times from 5 to $20 \mathrm{~min}$. No difference was found between the two differently treated particles.

(e) $K_{m}$ values for CMP- $N$-acetylneuraminic acid in the reactions with endogenous acceptors. It is not known whether or not the enzymes that catalyse the transference of sialyl groups to endogenous acceptors are the same as those that work with exogenous acceptors. Different $K_{m}$ values were found for CMP- $N$-acetylneuraminic acid when the different types of acceptors were used. With lactosylceramide as exogenous acceptor the $K_{m}$ value was $4 \times 10^{-5} \mathrm{M}$ (Arce, 1968); with endogenous acceptors and $1 \mathrm{mg}$ of particulate enzyme preparation for an incubation period of $3 \mathrm{~min}$, the $K_{m}$ value was $3 \times 10^{-6} \mathrm{M}$. It is uncertain whether these $K_{m}$ values are comparable. In the determination of $K_{m}$ with exogenous acceptor this was at saturating concentration. For the reasons given above it was considered that the endogenous acceptors were saturating the enzyme, but in working with gangliosides in various stages of complexity, it is possible that different enzymes were competing for the donor CMP- $N$-acetylneuraminic acid, whereas only lactosylceramide was present as exogenous acceptor.

Distribution of labelled components incorporated into endogenous acceptors. (a) General distribution. Three experiments were run in which the particles were incubated with (a) CMP- $N\left[{ }^{3} \mathrm{H}\right]$-acetylneuraminic acid, (b) simultaneously with CMP $-N\left[{ }^{3} \mathrm{H}\right]-$ acetylneuraminic acid and UDP- $N$-acetyl $\left[{ }^{14} \mathrm{C}_{1}\right]$ galactosamine and (c) simultaneously with CMP- $N$ $\left[{ }^{3} \mathrm{H}\right]$-acetylneuraminic acid and UDP-[U-14 $\left.\mathrm{C}\right]$ galactose. In the experiment with CMP $-N\left[{ }^{3} \mathrm{H}\right]$-acetyl-

Table 2. Distribution of $\left.\mathrm{N}^{3} \mathrm{H}\right]$-acetylneuraminic acid in gangliosides formed in vitro from endogenous acceptors

The incubation system contained : particles from $21 \mathrm{~g}$ of 15 -day-old-rat brain; CMP-N $\left.{ }^{3} \mathrm{H}\right]$-acetylneuraminic

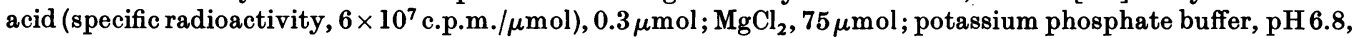
$600 \mu \mathrm{mol}$; final volume, $15 \mathrm{ml}$; temperature, $37^{\circ} \mathrm{C}$. The gangliosides were isolated and purified as described in the Experimental section.

\begin{tabular}{|c|c|c|c|c|c|}
\hline \multirow[b]{2}{*}{ Ganglioside } & \multirow[b]{2}{*}{$\begin{array}{l}\text { Incubation } \\
\text { time (min) }\end{array}$} & \multicolumn{2}{|c|}{ Neuraminidase-labile NANAc } & \multicolumn{2}{|c|}{ Neuraminidase-resistant NANAc* } \\
\hline & & $\begin{array}{l}\text { Sp. radioactivity } \\
\text { (c.p.m./ } / \mu \mathrm{mol} \text { ) }\end{array}$ & $\begin{array}{c}\text { Amount in- } \\
\text { corporated (nmol) }\end{array}$ & $\begin{array}{l}\text { Sp. radioactivity } \\
\text { (c.p.m. } / \mu \mathrm{mol})\end{array}$ & $\begin{array}{l}\text { Amount in- } \\
\text { corporated (nmol) }\end{array}$ \\
\hline G Lac $1\left(G_{M 3}\right)$ & 15 & 24933 & 62.3 & - & - \\
\hline G GNTr $1\left(G_{M 2}\right)$ & 15 & - & - & 11400 & 66 \\
\hline \multirow[t]{2}{*}{ G GNT $1\left(G_{M 1}\right)$} & $\mathbf{5}$ & - & - & 180 & 17 \\
\hline & 15 & - & 一 & 100 & 9 \\
\hline \multirow[t]{2}{*}{ G GNT $2 \mathrm{a}\left(\mathrm{G}_{\mathrm{D1a}}\right)$} & $\mathbf{5}$ & 11704 & 1311 & 140 & 15 \\
\hline & 15 & 16092 & 1802 & 130 & 14 \\
\hline \multirow{2}{*}{ G GNT $2 b\left(G_{D 1 b}\right)$} & $\mathbf{5}$ & 7442 & 434 & 180 & 10 \\
\hline & 15 & 23292 & 1359 & 140 & 8 \\
\hline \multirow[t]{2}{*}{ G GNT $3\left(G_{T 1}\right)$} & $\mathbf{5}$ & 8941 & 834 & 140 & 6 \\
\hline & 15 & 17352 & 1619 & 130 & 6 \\
\hline
\end{tabular}

* Approximate values. 
neuraminic acid it became evident that most of the NANAc incorporation was into a neuraminidaselabile position (Table 2). In a neuraminidaseresistant position only the sialyl group of the TaySachs ganglioside was substantially labelled; even in this case the results were not inconsistent with the possibility that this incorporation could have come from the addition of endogenous $N$-acetylgalactosamine to $\mathrm{G}$ Lac $1\left(\mathrm{G}_{\mathrm{M} 3}\right)$ (24933 c.p.m./ $\left./ \mu \mathrm{mol}\right)$ to form Tay-Sachs ganglioside (11 400 c.p.m./ $\mu \mathrm{mol}$ ) but this cannot be considered proven from this experiment. G GNT $2 a\left(G_{D 1 a}\right)$ was labelled in the neuraminidase-labile NANAc only, indicating that it was synthesized from G GNT $1\left(G_{M_{1}}\right)$ pre-existing in the particles. However, the specific radioactivity of the $N$-acetylgalactosamine (Table 3 ) or galactose (Table 5) moieties of G GNT $1\left(G_{M 1}\right)$, G GNT $2 a$ $\left(G_{D 1 a}\right)$, G GNT $2 b\left(G_{D 1 b}\right)$ and G GNT $3\left(G_{T 1}\right)$ indicate that the pools of these gangliosides are built independently between each other since no dilutions were observed in those moieties in passing from the pool of the monosialoganglioside to the pool of any of the disialogangliosides or from these to the trisialoganglioside.

(b) Pathway to Tay-Sachs ganglioside. The discrepancies in the pathway of synthesis of gangliosides apparent in experiments in vitro (see the introduction) appeared to be centred around the sequence of incorporation of the sialyl and galactosaminyl groups in G GNTr $1\left(G_{M_{2}}\right)$; the double labelling of endogenous acceptors may contribute to solving this problem provided that a favourable combination of concentrations of the acceptors was found. After simultaneous incubation of the particles with UDP- $N$-acetyl $\left[{ }^{14} \mathrm{C}_{1}\right]$ galactosamine and CMP- $N\left[{ }^{3} \mathrm{H}\right]$-acetylneuraminic acid, the ${ }^{14} \mathrm{C} /{ }^{3} \mathrm{H}$ molar ratio in the Tay-Sachs ganglioside formed during the incubation period should be $1: 1,1: 0$ or $0: 1$, when the starting materials for its synthesis were lactosylceramide, hematoside or aminoglycolipid respectively. Results in Table 4 were calculated two ways since substantial amounts of sugar nucleotides were found in the particles and at present it is not known whether a part or all of the particle nucleotides interchange with the labelled nucleotides present in the incubation medium. Whether the incorporations were calculated assuming that only added nucleotides $\left({ }^{14} \mathrm{C} /{ }^{3} \mathrm{H}\right.$ molar ratio $2.5: 1)$ or that all the recovered nucleotides were active donors in the system $\left({ }^{14} \mathrm{C} /{ }^{3} \mathrm{H}\right.$ molar ratio $37.7: 1$ ), the molar ratios of incorporation of $N$ acetyl $\left[{ }^{14} \mathrm{C}_{1}\right]$ galactosamine and $N\left[{ }^{3} \mathrm{H}\right]$-acetylneuraminic acid indicated that $G$ Lac $1\left(G_{M 3}\right)$ was a precursor quantitatively more important than G GNTr for the synthesis of G GNTr $1\left(G_{M_{2}}\right)$.

(c) Labelling of the disialoganglioside G GNT 2b $\left(G_{D 1 b}\right)$. The double-labelling experiments apparently solved the problem of whether or not the labile sialyl group attached by a $2 \rightarrow 8$ linkage to the sialyl group resistant to neuraminidase enters before

Table 3. Incorporation of $\mathrm{N}\left[{ }^{3} \mathrm{H}\right]$-acetylneuraminic acid and $\mathrm{N}$-acetyl $\left[{ }^{14} \mathrm{C}_{1}\right]$ galactosamine into endogenous gangliosides

The incubation system contained : particles from $35 \mathrm{~g}$ of 15-day-old-rat brain ; CMP-N $\left[{ }^{3} \mathrm{H}\right]$-acetylneuraminic acid (sp. radioactivity $12 \times 10^{7}$ c.p.m. $/ \mu \mathrm{mol}$ ), $0.5 \mu \mathrm{mol}$; UDP- $N$-acetyl $\left[{ }^{14} \mathrm{C}_{1}\right]$ galactosamine (sp. radioactivity $8.8 \times 10^{7}$ c.p.m. $\left./ \mu \mathrm{mol}\right), 0.05 \mu \mathrm{mol} ; \mathrm{MgCl}_{2}, 125 \mu \mathrm{mol} ; \mathrm{MnCl}_{2}, 125 \mu \mathrm{mol}$; potassium phosphate buffer, $\mathrm{pH} 6.8$, $1 \mathrm{mmol}$; final volume, $25 \mathrm{ml}$; incubated at $37^{\circ} \mathrm{C}$ for $15 \mathrm{~min}$. CMP- $N\left[{ }^{3} \mathrm{H}\right]$-acetylneuraminic acid (sp. radioactivity $7.2 \times 10^{7}$ c.p.m. $/ \mu \mathrm{mol}$ ) was isolated, after the reaction was stopped with ethanol, at $37^{\circ} \mathrm{C}, \mathrm{pH} 7.6$ for $10 \mathrm{~min}$. The precipitate was centrifuged, the supernatant was evaporated and CMP- $N$-acetylneuraminic acid was isolated from the residue as described by Warren \& Blacklow (1962). UDP- $N$-acetyl $\left[{ }^{14} C_{1}\right]$ galactosamine (sp. radioactivity $3.6 \times 10^{6}$ c.p.m./ $\mu \mathrm{mol}$ ) was isolated as described by McGarrahan \& Maley (1962) from the upper phase of the Folch's partition, after elimination of $\mathrm{KCl}$ by passing the solution through a column of Dowex$50\left(\mathrm{H}^{+}\right.$form) and precipitation of $\mathrm{Cl}^{-}$with $\mathrm{Ag}_{2} \mathrm{CO}_{3}$. Since no satisfactory constant radioactivities were obtained for sialyl groups of very low specific radioactivities in gangliosides in which sialyl groups with high specific radioactivities were present no attempt has been made to compare these sialyl groups with other components of low specific radioactivities.

Sp. activity ( $\mathrm{nmol}$ incorporated $/ \mu \mathrm{mol}$ of NANAc)

\begin{tabular}{|c|c|c|c|c|c|c|c|}
\hline \multirow[b]{3}{*}{ Ganglioside } & \multicolumn{4}{|c|}{ Calculated from added nucleotides } & \multicolumn{3}{|c|}{ Calculated from recovered nucleotides } \\
\hline & \multicolumn{2}{|c|}{ NANAc } & \multirow[b]{2}{*}{ GalNAc } & \multirow[b]{2}{*}{$\begin{array}{c}\text { GalNAc/NANAc } \\
\text { (labile) ratio }\end{array}$} & \multirow[b]{2}{*}{$\begin{array}{r}\text { Labile } \\
\text { NANAc }\end{array}$} & \multirow[b]{2}{*}{ GalNAc } & \multirow[b]{2}{*}{$\begin{array}{c}\text { GalNAc/NANAc } \\
\text { (labile) ratio }\end{array}$} \\
\hline & Resistant & Labile & & & & & \\
\hline G GNT $1\left(G_{M_{1}}\right)$ & 3.1 & - & 1.46 & - & - & 35.8 & - \\
\hline G GNT 2a $\left(G_{D 1 a}\right)$ & 2.2 & 135 & 3.73 & $0.028: 1$ & 225 & 91.1 & $0.405: 1$ \\
\hline G GNT 2b $\left(G_{D 1 b}\right)$ & 4.5 & 356 & 0.62 & $0.002: 1$ & 593 & 15.3 & $0.026: 1$ \\
\hline G GNT $3\left(G_{T 1}\right)$ & 3.8 & 435 & 2.16 & $0.005: 1$ & 709 & 52.8 & $0.074: 1$ \\
\hline
\end{tabular}


Table 4. Incorporation of $\mathrm{N}\left[{ }^{3} \mathrm{H}\right]$-acetylneuraminic acid and $\mathrm{N}$-acety $\left[{ }^{14} \mathrm{C}_{1}\right]$ galactosamine into endogenous Tay-Sachs ganglioside

The incubation system was as described in Table 3. Tay-Sachs ganglioside was added as carrier to the inactivated incubation mixture; the ganglioside that migrated chromatographically as Tay-Sachs ganglioside was then isolated, treated with neuraminidase and purified to constant specific radioactivity as described in the Experimental section.

Amount incorporated into Tay-Sachs ganglioside* (nmol)

\begin{tabular}{|c|c|c|c|c|c|c|}
\hline \multirow[b]{2}{*}{$\begin{array}{l}\text { Incubation } \\
\text { time (min) }\end{array}$} & \multicolumn{3}{|c|}{ Calculated from added nucleotide } & \multicolumn{3}{|c|}{ Calculated from recovered nucleotide $\dagger$} \\
\hline & NANAc & GalNAc & $\frac{\text { GalNAc }}{\text { NANAc }}$ ratio & NANAc & GalNAc & $\frac{\text { GalNAc }}{\text { NANAc }}$ ratio \\
\hline $\begin{array}{r}5 \\
15\end{array}$ & $\begin{array}{l}37.2 \\
48.4\end{array}$ & $\begin{array}{r}93 \\
126\end{array}$ & $\begin{array}{l}2.5: 1 \\
2.6: 1\end{array}$ & $\begin{array}{l}59.2 \\
77.4\end{array}$ & $\begin{array}{l}2322 \\
3024\end{array}$ & $\begin{array}{r}37.7: 1 \\
39: 1\end{array}$ \\
\hline
\end{tabular}

* The NANAc of Tay-Sachs ganglioside was resistant to the neuraminidase preparation used.

$\dagger$ The specific radioactivities of recovered nucleotides are indicated in Table 3.

\section{Table 5. Incorporation of $\mathrm{N}\left[{ }^{3} \mathrm{H}\right]$-acetylneuraminic acid and $\left[\mathrm{U}-{ }^{14} \mathrm{C}\right]$ galactose into endogenous gangliosides}

The incubation system contained : particles from $37 \mathrm{~g}$ of 15 -day-old-rat brain; CMP- $N\left[{ }^{3} \mathrm{H}\right]$-acetylneuraminic acid (sp. radioactivity $12 \times 10^{7}$ c.p.m. $/ \mu \mathrm{mol}$ ), $0.4 \mu \mathrm{mol}$; UDP-[U-14 C]galactose (sp. radioactivity $4.9 \times 10^{7}$ c.p.m./ $\mu \mathrm{mol}$ ), $0.4 \mu \mathrm{mol} ; \mathrm{MgCl}_{2}, 125 \mu \mathrm{mol} ; \mathrm{MnCl}_{2}, 125 \mu \mathrm{mol}$; potassium phosphate buffer, $\mathrm{pH} \mathrm{6.8,} 1 \mathrm{mmol}$, final volume, $25 \mathrm{ml}$; incubated at $37^{\circ} \mathrm{C}$ for $7 \mathrm{~min}$. The gangliosides were isolated, treated with neuraminidase and purified as described in the Experimental section. Since no satisfactory constant radioactivities were obtained for sialyl groups of very low specific radioactivities in gangliosides in which sialyl groups with high specific radioactivities were present, no attempt has been made to compare these sialyl groups with other components of low specific radioactivities.

Sp. activity ( $\mathrm{nmol}$ incorporated $/ \mu \mathrm{mol}$ of ganglioside)

\begin{tabular}{|c|c|c|c|c|}
\hline \multirow[b]{2}{*}{ Ganglioside } & \multicolumn{2}{|c|}{ NANAc } & \multirow[b]{2}{*}{ Galactose } & \multirow{2}{*}{$\begin{array}{c}\text { Galactose/NANAc } \\
\text { (labile) ratio }\end{array}$} \\
\hline & Resistant & Labile & & \\
\hline G Lac $1\left(G_{M 3}\right)$ & - & 1166 & 571 & - \\
\hline G GNTr $\left(G_{M_{2}}\right)$ & 370 & - & 91 & - \\
\hline G GNT $1\left(G_{M_{1}}\right)$ & 14.4 & - & 16.6 & - \\
\hline G GNT $2 \mathrm{a}\left(\mathrm{G}_{\mathrm{D} 1 \mathrm{a}}\right)$ & 10.8 & 275 & 20.9 & $0.08: 1$ \\
\hline G GNT $2 b\left(G_{D 1 b}\right)$ & 8.8 & 191 & 16.4 & $0.09: 1$ \\
\hline G GNT $3\left(G_{T 1}\right)$ & 15.3 & 496 & 23.0 & $0.05: 1$ \\
\hline
\end{tabular}

the galactosaminyl group. Table 3 shows that the $N$-acetyl $\left[{ }^{14} \mathrm{C}_{1}\right]$ galactosamine/labile $N\left[{ }^{3} \mathrm{H}\right]$-acetylneuraminic acid molar ratio calculated both from added nucleotides or from recovered nucleotides was lower than unity, indicating that most of the synthesis of G GNT $2 b\left(G_{D 1 b}\right)$ did not occur via G Lac 2. Table 5 shows that in G GNT $2 b\left(G_{D 1 b}\right)$ the sialyl group entered more labile NANAc than galactose (galactose/labile NANAc molar ratio $0.09: 1)$, which indicated that G GNT $1\left(G_{M_{1}}\right)$ was a precursor of G GNT $2 b\left(G_{D 1 b}\right)$.

(d) Labelling of trisialoganglioside. To obtain information on the sequence of incorporation of the two labile sialyl groups of G GNT $3\left(G_{T 1}\right)$, this ganglioside was isolated from the products of the incubation of particles with CMP- $N\left[{ }^{3} \mathrm{H}\right]$-acetylneuraminic acid. A sample of this preparation was incubated with neuraminidase in conditions designed to release completely the labile sialyl groups (total labile; for details see the Experimental section). Another sample of the same preparation was incubated with diluted neuraminidase so that the maximum possible amount of G GNT $2 b\left(G_{D 1 b}\right)$ was obtained. In the experiment described in Table $6,33 \%$ of the theoretical amount of G GNT 2b $\left(G_{D 1 b}\right)$ was obtained; this was treated with neuraminidase under the standard conditions to release the labile NANAc attached through a $2 \rightarrow 8$ linkage to the resistant NANAc residue. The specific radioactivity of the released NANAc was determined (labile $2 \rightarrow 8$ ). Table 6 shows that most of the labelling was in the sialyl group attached to position 3 of the terminal galactose, showing that in the conditions of our experiment most of 
Table 6. Distribution of labile $\mathrm{N}\left[{ }^{3} \mathrm{H}\right]$-acetylneuraminic acid in the trisialoganglioside formed in vitro from endogenous acceptors

The incubation system contained: particles from $30 \mathrm{~g}$ of 15-day-old-rat brain; CMP- $N\left[{ }^{3} \mathrm{H}\right]$-acetylneuraminic acid (sp. radioactivity $10 \times 10^{6}$ c.p.m. $/ \mu \mathrm{mol}$ ), $0.4 \mu \mathrm{mol}$; $\mathrm{MgCl}_{2}, 100 \mu \mathrm{mol}$; potassium phosphate buffer, pH6.8, $800 \mu \mathrm{mol}$; final volume, $20 \mathrm{ml}$; incubated for $15 \mathrm{~min}$ at $37^{\circ} \mathrm{C}$. G GNT $3\left(\mathrm{G}_{\mathrm{T} 1}\right)$ was isolated, purified and treated with neuraminidase as described in the Experimental section.

\section{Labile NANAc}

Incorporation (c.p.m./ $\mu \mathrm{mol}$ of NANAc)

Total

$2 \rightarrow 8$ linkage (to resistant NANAc)

$2 \rightarrow 3$ linkage (to terminal galactose)

15004

600

30374

the G GNT $3\left(G_{T 1}\right)$ was synthesized from G GNT $2 b$ $\left(G_{D 1 b}\right)$.

\section{DISCUSSION}

The presence of sialyltransferases for gangliosides in all the subcellular organelles (Arce et al. 1966) indicated that each organelle synthesizes its own gangliosides; this was supported by experiments in vivo in which no sequential but simultaneous labelling of the gangliosides in different organelles was found (Rubiolo de Maccioni \& Caputto, 1968; Harzer, Jatzkewitz \& Sandhoff, 1969). In addition, in the present work it was shown that rat brain particles are able to complete the formation of all the major gangliosides by using endogenous precursors attached to the particles and added watersoluble CMP- $N$-acetylneuraminic acid.

Some of the experiments in this work were devised to gain a first insight on the problem of the synthesis of gangliosides as membrane constituents. For this reason any treatment damaging the integrity of the particles, as, for instance, addition of detergents, was avoided, and so the system was expected to be essentially compartmentalized. That this was obtained was indicated by the linear curve of activity versus concentration of particles. This showed that the particles were active in discrete compartments; if interaction between substrates and enzymes from different particles had played an important part in the measured reactions, an exponential curve would have been obtained; any substrate from a given particle is in exogenous position to any enzyme from another particle, and there was no reason to assume that under the conditions of exogenous substrates they were at saturating concentrations all along the range of particle concentrations tested. In a system in which the largest possible compartments were the particles themselves, it was notable that the curve of activity versus time was that of a zero-order rather than a first-order reaction. On average, this means that in each particle the pools of acceptors are at saturating concentrations for the catalytic units in the same particle. But at the same time, the heat-inactivation experiments showed that activity and acceptor capacity of the preparations decreased simultaneously. One possible explanation is that a substrate is such for one enzyme or catalytic centre only and once this is inactivated the substrate cannot be used by another enzyme. We suggest that this observation fits well with those models of membrane in which enzymes and lipids are interdispersed in such a way that the lipids are distributed between the enzyme molecules (Sjöstrand, 1968) In these models relatively small pools may be saturating the enzyme with which it is in almost continuous contact but once that particular enzyme is inactivated the substrate cannot get in contact with another enzyme.

From the specific radioactivity of common moieties of gangliosides (such as $\mathrm{N}$-acetylgalactosamine and galactose), no indications were found of precursor-product relationships between the monoand di-sialogangliosides or between these and the trisialoganglioside, since there was no definite radioactive dilution between them. This does not necessarily mean that in building up a complex ganglioside it does not pass through the stages of less complex compounds of the same group; but evidently, provided that this is the mechanism of synthesis, only a small part of each pool is formed of stages in the formation of the more complex compounds. Whether the different stages travel on the surface of the corresponding enzymes or the acceptor is in a set position and in it the total compound is built up, there is no way of deciding at present. Our attempts to demonstrate reciprocal interference between endogenous and exogenous acceptors on the incorporation of NANAc failed; because of the uncertainties as to the conditions of the endogenous substrate no definite conclusion can be drawn from these experiments but they indicate that the enzymes working with acceptors in these two positions are different.

The rigid arrangement suggested by our findings provides an explanation for the independent biosynthesis of each of the different gangliosides found by Suzuki \& Korey (1964) in experiments in vivo and confirmed by us (A. Arce, H. J. Maccioni \& R. Caputto, unpublished work). However, contrary to what has been reported in those experiments the labelling in vitro was found almost exclusively in the neuraminidase-labile sialyl groups. The results suggest that most of the incorporation of sialyl groups was by addition to hematoside or to more complex stages in the building up of gangliosides. 


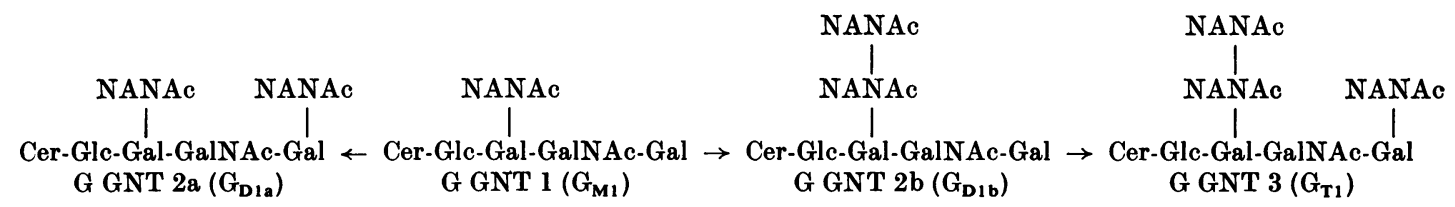

Scheme 1. Pathways for the synthesis of gangliosides suggested by their labelling in particles incubated with CMP- $N\left[{ }^{3} \mathrm{H}\right]$-acetylneuraminic acid, UDP- $N$-acetyl $\left[{ }^{14} \mathrm{C}_{1}\right]$ galactosamine and UDP-[U-14 C]galactose. Abbreviation: Cer, ceramide (2- $N$-acylsphingosine).

Very little of the major gangliosides was synthesized by starting at the lactosylceramide stage even in the experiments in which the particles were incubated with CMP- $N$-acetylneuraminic acid and UDPgalactose simultaneously. Since determinations of UDP- $N$-acetylgalactosamine in the particles showed that this was at a higher concentration than total (endogenous plus added) CMP- $N$-acetylneuraminic acid, the lack of nucleotides was not the explanation for the failure to synthesize mono-, di-, and tri-sialogangliosides from lactosylceramide. This again suggests that the membrane is in a rigid arrangement and that the endogenous nucleotides are not free to reach every possible reacting position; alternatively the requirements of the position and not the presence of donors and acceptors determines whether the synthesis will proceed further. Another possibility is that sialidase-resistant NANAc was incorporated but passed undetected because it was transferred from an unlabelled precursor, which, because of its position or its chemical nature, is better able to act as donor than the CMP- $N$. acetylneuraminic acid in the supernatant. The complete understanding of the synthesis of gangliosides will have to wait for the clarification of these points; in the meantime the present experiments with endogenous acceptors provide some information on pathways occurring with donors present in the fluid surrounding the membranes. Probably, this is a further step towards solving the problem of the synthesis in vivo since the experiments involved more physiological conditions than exist when donors and acceptors are added from outside.

The pathways proposed for G Lac $1\left(G_{M 3}\right)$ by Arce et al. (1966) and by Kaufman et al. (1966) and for G GNT 2a $\left(G_{D_{1 a}}\right)$ by Kaufman et al. (1968) are in agreement with the labelling of the endogenous acceptors. To study the pathway for G GNTr 1 $\left(G_{M 2}\right)$ and G GNT $2 b\left(G_{D 1 b}\right)$ double labelling was needed; the interpretation of the experiment in which G GNTr $1\left(\mathrm{G}_{\mathrm{M} 2}\right)$ was labelled with $N \cdot\left[{ }^{3} \mathrm{H}\right]$ acetylneuraminic acid and $N$-acetyl[ $\left[{ }^{14} \mathrm{C}_{1}\right]$ galactosamine indicated that 2.5 times as much G GNTr 1 $\left(G_{M 2}\right)$ was formed from hematoside as from G GNTr. If the $N$-acetylgalactosamine/NANAc incorporation ratio is calculated from the specific radio- activities of recovered nucleotides the difference increases but it is not certain whether all or part of the endogenous nucleotides present in the particle intervenes as a donor.

Simultaneous labelling with $N\left[{ }^{3} \mathrm{H}\right]$-acetylneuraminic acid and $N$-acetyl $\left[{ }^{14} \mathrm{C}_{1}\right]$ galactosamine showed that in this system the labelling of G GNT $2 b\left(G_{D 1 b}\right)$ through the pathway

$$
\text { G GNTr } 1\left(G_{M 2}\right) \rightarrow \text { G GNT } 2 b\left(G_{D 1 b}\right)
$$

is at least 400 times higher than the pathway G Lac $2 \rightarrow$ G GNT $2 b\left(\mathrm{G}_{\mathrm{D} 1 \mathrm{~b}}\right)$ predicted from structural considerations by Kaufman et al. (1968) and by Wiegandt (1968). Simultaneous labelling with $N\left[{ }^{3} \mathrm{H}\right]$-acetylneuraminic acid and $\left[\mathrm{U}_{-}{ }^{14} \mathrm{C}\right]$ galactose showed that the pathway was G GNTr $1\left(G_{M_{2}}\right) \rightarrow$ G GNT $1\left(G_{M 1}\right) \rightarrow$ G GNT $2 b\left(G_{D 1 b}\right)$.

In connection with the synthesis of G GNT $3\left(G_{T 1}\right)$ the results of endogenous incorporation of NANAc showed that the precursor is G GNT $2 b\left(G_{D 1 b}\right)$ since the sialyl group found labelled after incubation of the particles with CMP- $N\left[{ }^{3} \mathrm{H}\right]$-acetylneuraminic acid was that bound to the galactose at the non-reducing end. Kaufman et al. (1968) and Wiegandt (1968) suggested this pathway for the synthesis of G GNT $3\left(G_{T 1}\right)$ but as far as we know the first experimental evidence for it is the one described in the present work. The pathway for the synthesis of the G GNT $2 a\left(G_{D 1 a}\right), G$ GNT $2 b\left(G_{D 1 b}\right)$ and G GNT $3\left(G_{T 1}\right)$ suggested by the incorporation of labelled components to endogenous acceptors is depicted in Scheme 1.

This investigation was supported in part by a Grant from the Consejo Nacional de Investigaciones Cientificas y Técnicas, Argentine Republic, and by Grant NB04781 from National Institutes of Health, U.S. Public Health Service. The helpful criticism of Dr H. S. Barra and Dr M. A. de Billerbeck is acknowledged.

\section{REFERENCES}

Arce, A. (1968). Ph.D. Thesis: Universidad Nacional de Córdoba, Argentina.

Arce, A., Maccioni, H. J. \& Caputto, R. (1966). Archs Biochem. Biophys. 116, 152. 
Barra, H. S., Cumar, F. A., \& Caputto, R. (1969). J. biol. Chem. 244, 6233.

Burton, R. M. (1963). J. Neurochem. 10, 503.

Cumar, F. A., Barra, H. S., Maccioni, H. J. \& Caputto, R. (1968). J. biol. Chem. 243, 3807.

Eichberg, J., Whittaker, V. P. \& Dawson, R. M. C. (1964). Biochem. J. 92, 91.

Folch, J., Lees, M. \& Sloane-Stanley, G. H. (1957). J. biol. Chem. 226, 497.

Gatt, S. (1965). J. Neurochem. 12, 311.

Handa, S. \& Burton, R. M. (1969). Lipids, 4, 589.

Harzer, K., Jatzkewitz, H. \& Sandhoff, K. (1969). J. Neurochem. 16, 1279.

Kanfer, J., Blacklow, R. S., Warren, L. \& Brady, R. O. (1964). Biochem. biophys. Res. Commun. 14, 287.

Kaufman, B., Basu, S. \& Roseman, S. (1966). Proc. 3rd int. Symp. Cerebral Sphingolipidosis, p. 193. Ed. by Aronson, S. M. \& Volk, B. N. New York: Pergamon Press Inc.

Kaufman, B., Basu, S. \& Roseman, S. (1968). J.biol.Chem. 243, 5804.

Ledeen, R., Salsman, K. \& Cabrera, M. (1968). Biochemistry, Easton, 7, 2287.

Lehninger, A. (1968). Proc. natn. Acad. Sci. U.S.A. 60, 1069.

Lowry, O. H., Rosebrough, N. J., Farr, A. L. \& Randall, R. J. (1951). J.biol. Chem. 193, 265.
McGarrahan, J. F. \& Maley, F. (1962). J. biol. Chem. 237, 2458.

Miettinen, T. \& Takki-Luukkainen, I. T. (1959). Acta chem. scand. 13, 856.

Penick, R. S., Meisler, M. H. \& McCluer, R. (1966). Biochim. biophys. Acta, 116, 279.

Reiner, J. M. (1959). Behaviour of Enzyme System, p. 89. Minneapolis: Burgess Publishing Co.

Roseman, S. (1962). Proc. natn. Acad. Sci. U.S.A. 48, 437.

Rubiolo de Maccioni, A. H. \& Caputto, R. (1968). J. Neurochem. 15, 1257.

Sjöstrand, F. S. (1968). Regulatory Functions of Biological Membranes, p. 1. London: Elsevier Publishing Co.

Suzuki, K. \& Chen, G. C. (1967). J. Neurochem. 14, 911.

Suzuki, K. \& Korey, S. R. (1964). J. Neurochem. 11, 647.

Svennerholm, L. (1957). Biochim. biophys. Acta, 24, 604 .

Svennerholm, L. (1963). J. Neurochem. 10, 613.

Svennerholm, L. (1964). J. Lipid Res. 5, 145.

Warren, L. (1959). J. biol. Chem. 234, 1971.

Warren, L. \& Blacklow, R. S. (1962). J. biol. Chem. 237, 3527.

Wells, M. A. \& Dittmer, J. C. (1963). Biochemstry, Easton, $2,1259$.

Wiegandt, H. (1968). Angew. Chem. 3, 89.

Yip, M. C. M. \& Dain, J. A. (1969). Lipids, 4, 270. 